\title{
Airway Clearance With an Optimized Mechanical Insufflation-Exsufflation Maneuver
}

\author{
Marcia S Volpe PhD RRT, Juliane M Naves RRT, Gabriel G Ribeiro RRT, \\ Gualberto Ruas PhD RRT, and Marcelo B P Amato PhD MD
}

\begin{abstract}
BACKGROUND: Standard mechanical insufflation-exsufflation (MI-E) therapy is applied with fast insufflation-exsufflation pressures to achieve high peak expiratory flows (PEF) and assist airway clearance. No attention is given to the resultant high peak inspiratory flows (PIF), although it may impair secretion removal. It has been proposed that an expiratory flow bias (ie, PEF higher than PIF) might be the key determinant for mucus clearance instead of the PEF alone. We examined the effects of 2 MI-E maneuvers, standard versus optimized, with fast and slow insufflation, respectively, along with different MI-E pressure settings on secretion displacement in 3 lung-impedance scenarios that simulated a patient on mechanical ventilation. METHODS: The MI-E device was connected to a lung model that simulated a patient on mechanical ventilation. Known quantities of mucus simulant were injected into the system and exposed to various MI-E ventilation conditions. Mucus movement was examined with image-analysis software. RESULTS: The optimized MI-E maneuver resulted in a much lower PIF $(37.5 \mathrm{~L} / \mathrm{min}$ [interquartile range, $24.9-47.9 \mathrm{~L} / \mathrm{min}$ ] vs $101.8 \mathrm{~L} / \mathrm{min}$ [interquartile range, 89.1-115.7 L/min], $P<.001$ ). Consequently, the expiratory flow bias, expressed by PEF:PIF and the PEF-PIF difference, was much higher in the optimized maneuver. The higher expiratory flow bias in the optimized maneuver displaced the mucus outward, with a difference of $2.6 \mathrm{~cm}$ compared with the standard maneuver. Multivariate analysis revealed that the type of maneuver (optimized vs standard), PEF-PIF difference and MI-E pressure gradient were significantly correlated with mucus displacement $\left(r^{2}=0.817, P<.001\right)$, whereas the PEF was not. PEF:PIF and the PEF-PIF difference were lower in the obstructive lung scenario when compared with the restrictive and normal lung scenarios. CONCLUSIONS: The optimized MI-E maneuver, applied with slow insufflation, resulted in a higher expiratory flow bias, which made the therapy more effective at moving mucus outward, compared with the standard MI-E maneuver, typically applied with fast insufflation. Key words: respiratory therapy; mechanical insufflation-exsufflation; mechanical ventilation; airway clearance. [Respir Care 2018;63(10):1214-1222. (C 2018 Daedalus Enterprises]
\end{abstract}

\section{Introduction}

Mechanical insufflation-exsufflation (MI-E) is applied for airway clearance in patients with impaired cough, ei-

\footnotetext{
Dr Volpe is affiliated with the Department of Human Movement Sciences, Federal University of São Paulo, Santos, São Paulo, Brazil. Ms Naves, Mr Ribeiro, and Dr Ruas are affiliated with the Department of Applied Physiotherapy, Federal University of Triângulo Mineiro, Uberaba, Minas Gerais, Brazil. Dr Amato is affiliated with the Pulmonary Division, Cardio-Pulmonary Department, Heart Institute (Incor), Hospital Das Clínicas da FMUSP, University of Sao Paulo, São Paulo, Brazil.
}

The authors have disclosed no conflicts of interest. ther through an endotracheal or tracheostomy tube or a face mask..$^{1,2}$ Currently, the use of MI-E is considered the most effective treatment to clear secretions in patients with respiratory muscle weakness caused by a wide variety of neuromuscular diseases. ${ }^{1,3}$ To assist with secretion removal, MI-E needs to create a peak expiratory flow (PEF) high

Correspondence: Marcia S Volpe PhD RRT, Department of Human Movement Sciences, Federal University of São Paulo, 136 Rua Silva Jardim, Santos, Brazil 11015-020. E-mail: marciasvolpe@gmail.com.

DOI: $10.4187 /$ respcare. 05965 
enough to provide adequate shear and velocity to loosen and move secretions toward the mouth where it can be suctioned or expectorated. ${ }^{1}$ A cough peak flow of $>160 \mathrm{~L} / \mathrm{min}$ is advocated to be the threshold to clear airway secretions

\section{See the Related Editorial on Page 1318}

from central airways. ${ }^{4,5}$ Indeed, MI-E clinical efficacy is frequently assured, owing to its capacity of providing PEF of $>160 \mathrm{~L} / \mathrm{min}^{6,7}$

Three decades ago, the influence of peak inspiratory flow (PIF) and its relationship with PEF on secretion management in the patient on mechanical ventilation was raised $^{8-11}$ but, until recently, was largely ignored. Mucus transport is proposed as being mainly influenced by flow bias, which occurs when the peak or mean flows during the inspiratory and expiratory phases differ substantially. ${ }^{12}$ The flow bias can move mucus by using the 2-phase gasliquid transport mechanism and is usually expressed as the ratio (PEF:PIF) or difference (PEF - PIF) between the peak flows. ${ }^{9}$ The critical factors that affect mucus transport by this mechanism include inspiratory-expiratory air velocity, viscosity of mucus, and thickness of the mucus layer. ${ }^{13}$ When considering which one is the highest, PIF or $\mathrm{PEF}$, an inspiratory or expiratory flow bias is established and leads the net mucus movement in the same direction of the flow bias toward the lungs or the glottis, respectively. According to studies in animals and lung models, PEF:PIF higher than $1.1^{8,9}$ and a PEF-PIF difference higher than $17 \mathrm{~L} / \mathrm{min}^{12}$ are critical thresholds for the removal of lung secretions during mechanical ventilation.

Therefore, strategies that reduce the PIF without compromising the PEF and, as a result, increase the expiratory flow bias might be of interest for airway clearance. ${ }^{14}$ However, during standard MI-E therapy, no attention is given to PIFs and, because fast insufflation pressures are usually applied, the resultant PIF might be very high, which may reduce its efficacy.

We hypothesized that the MI-E maneuver could be optimized if the PIF was reduced by slowly shifting the manual control lever to the inhale position in association with no PEF changes, which, consequently, would result in a higher expiratory flow bias. The primary aim of the present study was to explore the effects of 2 MI-E maneuvers, standard versus optimized, with fast and slow insufflation, respectively, on secretion displacement. Because the optimal MI-E pressure settings for artificial airways are not well known, ${ }^{15}$ we also studied the associated effects of different MI-E pressure settings in 3 lung-impedance scenarios that simulated a patient on mechanical ventilation.

\section{QUICK LOOK}

\section{Current knowledge}

Mechanical insufflation-exsufflation (MI-E) therapy is usually applied with fast in-exsufflation pressures to create high peak expiratory flows and assist with airway clearance. However, this standard maneuver may also generate high peak inspiratory flows, which may impair secretion removal. It has been proposed that airway clearance maneuvers require expiratory flow bias and not only high peak expiratory flows to be effective.

\section{What this paper contributes to our knowledge}

In a lung model that simulated a patient on mechanical ventilation, the MI-E maneuver was optimized by applying slow lung insufflation, which reduced the peak inspiratory flow and, consequently, increased the expiratory flow bias. As a result, the optimized MI-E maneuver was more effective for mucus clearance.

\section{Methods}

\section{Study Design}

This laboratory study was conducted at Federal University of Triângulo Mineiro, Minas Gerais, Brazil.

\section{Mucus Simulant}

Synthetic solutions with standardized viscoelastic properties similar to human mucus were formulated according to previously described methods. ${ }^{16}$ A known quantity ( $\left.1.5 \mathrm{~g}\right)$ of polyethylene oxide powder (Sentry Polyox WSR Coagulant, Dow Chemicals, Wilmington, Delaware) was dissolved in $100 \mathrm{~mL}$ of filtered water at $100^{\circ} \mathrm{C}$. The solution thickness at the concentration prepared (1.5\%) simulated normal airway mucus.

\section{Mucus-Movement Measurements}

A transparent tubing (inner diameter $1 \mathrm{~cm}$, length $30 \mathrm{~cm}$ ) was positioned horizontally on a light box, and mucus movement was photographed with a 12-megapixel camera fixed $1.30 \mathrm{~m}$ above and perpendicular to the light box. Photographs of the mucus simulant position were obtained before and after 5 cycles of MI-E were applied according to the study protocol. Image-analysis software (Sigmascan, Statistical Solutions, Saugus, Massachusetts) was used to evaluate mucus movement by measuring the mucus area in the number of pixels. Mucus displacement after applying MI-E maneuvers was evaluated by the displacement of 


\section{Model of an Optimized MI-E Maneuver}

the center of mass. The image analysis software calculates the center of mass by determining a central location of the "object" after multiplying all pixels by their relative intensities. More details of the technique used to measure mucus movement have been described elsewhere. ${ }^{12}$

\section{Study Protocol}

The study comprised 2 experiments in which we tracked the displacement of mucus simulant after the application of MI-E to the airways of a lung model system. The test lung (Intermed, São Paulo, Brazil) used was ventilated via transparent tubing with a manual MI-E (Cough Assist, Model CM-3200, Philips Respironics, Murrysville, Pennsylvania). Respiratory mechanics were measured proximally (between the tip of the transparent tubing and the MI-E circuit) with the respiratory monitor $\mathrm{CO}_{2} \mathrm{SMO}$ Plus (Novametrix Medical Systems, Wallingford, Connecticut).

Three lung-impedance scenarios, to widen the study results for different lung diseases, were simulated in the 2 experiments, setting compliance (C) of the test lung and changing the linear resistor $(\mathrm{R})$. The 3 scenarios simulated in sequence were (a) normal $\left(\mathrm{R}=5 \mathrm{~cm} \mathrm{H}_{2} \mathrm{O} / \mathrm{L} / \mathrm{s}\right.$, $\left.\mathrm{C}=0.05 \mathrm{~L} / \mathrm{cm} \mathrm{H}_{2} \mathrm{O}\right)$; (b) obstructive $\left(\mathrm{R}=20 \mathrm{~cm} \mathrm{H}_{2} \mathrm{O} / \mathrm{L} / \mathrm{s}\right.$, $\left.\mathrm{C}=0.05 \mathrm{~L} / \mathrm{cm} \mathrm{H}_{2} \mathrm{O}\right)$; and (c) restrictive $(\mathrm{R}=5 \mathrm{~cm}$ $\mathrm{H}_{2} \mathrm{O} / \mathrm{L} / \mathrm{s}, \mathrm{C}=0.02 \mathrm{~L} / \mathrm{cm} \mathrm{H}_{2} \mathrm{O}$ ). In general, we hypothesized that combinations of $\mathrm{C}$ and $\mathrm{R}$ that resulted in shorter time constants should promote higher PEFs and potentially a higher expiratory flow bias.

In each experiment, $1 \mathrm{~mL}$ of mucus simulant was injected into the center of the tubing and was allowed to settle for 3-5 min before taking the initial photograph. After applying specific insufflation pressure/exsufflation pressure (+IP/-EP) for 5 cycles, another photograph was taken. The photographs were analyzed to assess mucus simulant displacement. After each experiment, the tube was washed, air-dried, and repositioned on the light box for the next experiment. In all the experiments, the MI-E device was operated by a trained researcher (GGR) of our group and the inhale flow setting was adjusted at full setting (increased flow).

\section{Experiment 1. Clinical Practice Simulation: Standard MI-E Maneuver}

The objective of this experiment was to simulate the application of MI-E as it is usually applied in clinical practice (ie, $3-5$ cycles, inspiratory time $\left[\mathrm{T}_{\mathrm{I}}\right]$ of $3 \mathrm{~s}$ and expiratory time of $2 \mathrm{~s}$, with fast pressure rise time for both insufflation and exsufflation phases). The + IP ranged from 30 to $50 \mathrm{~cm} \mathrm{H}_{2} \mathrm{O}$ and $-E P$ ranged from -30 to $-60 \mathrm{~cm}$ $\mathrm{H}_{2} \mathrm{O}$. Nine $+\mathrm{IP} /-\mathrm{EP}$ trials were investigated in sequence: $+30 /-30,+30 /-40,+30 /-50,+30 /-60,+40 /-40$, $+40 /-50,+40 /-60$, and $+50 /-50,+50 /-60 \mathrm{~cm} \mathrm{H}_{2} \mathrm{O}$.
Although $+\mathrm{IP} /-\mathrm{EP}$ frequently applied are $+30 /-30 \mathrm{~cm}$ $\mathrm{H}_{2} \mathrm{O}$ or $+40 /-40 \mathrm{~cm} \mathrm{H}_{2} \mathrm{O}, 6,17-19$ we also wanted to explore the effects of asymmetric $+\mathrm{IP} /-\mathrm{EP}$ on mucus displacement. After adjusting $+\mathrm{IP} /-\mathrm{EP}$, the manual control lever was rapidly shifted to the inhale position and +IP was maintained over approximately $3 \mathrm{~s}$. The manual control lever was then rapidly shifted to the exhale position and $-\mathrm{EP}$ was held for $\sim 2 \mathrm{~s}$. This cycle was performed 5 times without a pause in between. All $9+$ IP/-EP trials were applied in sequence for the 3 lung-impedance scenarios.

\section{Experiment 2. Modified MI-E Insufflation Phase: Optimized MI-E Maneuver}

In this experiment, the manual control lever was slowly shifted to the inhale position over $4-5 \mathrm{~s}$ and held at the set + IP for at least $0.5 \mathrm{~s}$. The objective was to generate the lowest PIF in the artificial airways to optimize the expiratory flow bias. During the exsufflation phase, the manual control lever was rapidly shifted to the exhale position and held for $\sim 2 \mathrm{~s}$. This cycle was performed 5 times. The return of the control lever to the neutral position at the end of the exsufflation phase was done slowly, which resulted in a short pause between the cycles. Otherwise, a significant PIF would occur in the airways (before the insufflation phase was started) associated with the termination of exsufflation as lung volume returned to functional residual capacity. ${ }^{6}$ The same +IP/-EP trials investigated in experiment 1 were examined here.

\section{Data Analysis}

Data acquired by the $\mathrm{CO}_{2} \mathrm{SMO}$ Plus monitor were filtered and sampled at $100 \mathrm{~Hz}$. Variable values for each cycle were stored for subsequent analysis by attaching a computer, which was running complementary software (Analysis Plus, Novametrix Medical Systems, Wallingford, Connecticut) to the monitor. For each trial in experiments 1 and 2, at least 3 cycles were selected and averaged to obtain the values of $+\mathrm{IP},-\mathrm{EP}, \mathrm{T}_{\mathrm{I}}, \mathrm{PIF}, \mathrm{PEF}$, and tidal volume. The derived variables were then calculated: the difference between the modulus of PEF and PIF (PEFPIF difference), the corresponding ratio (PEF:PIF), and the difference of pressure settings (+IP/-EP gradient), calculated as the difference of the modulus of inspiratory and expiratory pressures. The primary outcome was the difference in mucus displacement (measured in $\mathrm{cm}$ ) induced by MI-E maneuvers (standard vs optimized). Secondary outcomes were the effects of other ventilation variables and lung-impedance scenarios on mucus displacement. 


\section{Statistical Analysis}

Data are shown as median and $25-75 \%$ interquartile range. The Mann-Whitney test was used to compare ventilation variables and mucus displacement between the 2 MI-E maneuvers (standard vs optimized). The KruskalWallis test was used to compare the same variables among the lung-impedance scenarios. Uni- and multivariate regression analyses were used to evaluate the influence of the type of maneuver (standard vs optimized), PEF, PEF: PIF, PEF-PIF difference, +IP, -EP, +IP/-EP gradient, and lung-impedance scenarios on mucus displacement. All significant or nearly significant parameters $(P<.10)$ of univariate analysis were forced into a stepwise multiple logistic-regression model to evaluate the independent role of each variable. The elected models were consistent during forward and backward selection of variables. To comply with normality assumptions, the mucus displacement variable had a square-root transformation before entering the regression model. For all comparisons, the 2-sided significance level was set at 05 . Statistical analysis was performed with SPSS software version 18.0 (SPSS, Chicago, Illinois).

\section{Results}

All $9+$ IP/-EP trials were performed twice for experiment 1 , and they were performed once for experiment 2 , for each one of the 3 lung-impedance scenarios. Therefore, 54 and 27 trials were conducted in experiments 1 and 2, respectively, totalizing 81 tested conditions. However, 2 trials $(+50 /-60$, obstructive scenario) were excluded from analyzes owing to errors in data acquisition.

\section{Standard Versus Optimized MI-E Maneuver}

Pressure and flow curves of 2 MI-E cycles performed according to the investigated maneuvers are illustrated in Figure 1. The optimized maneuver resulted in a much lower PIF and a slightly lower PEF compared with the standard maneuver (Fig. 1, Table 1). Consequently, both the PEF:PIF and the PEF-PIF difference were higher in the optimized maneuver ( $\sim 2.8$ and 2.5 times greater, respectively). The greater expiratory flow bias in the optimized maneuver displaced the mucus center-of-mass outward, with a difference of $2.6 \mathrm{~cm}$ when compared with the standard maneuver (Table 1). To deliver a lower PIF, insufflation was performed at a slower pace, which generated a $T_{I} 2.3 \mathrm{~s}$ longer in the optimized MI-E maneuver. No differences in tidal volume, + IP, or $-\mathrm{EP}$ between the two maneuvers were found.

The PEF-PIF difference and mucus displacement for each $+\mathrm{IP} /-\mathrm{EP}$ trial, and for each maneuver, in the 3 lungimpedance scenarios are illustrated in Figure 2. Note that, for each +IP/-EP trial, the slow insufflation in the optimized maneuver resulted in a higher PEF-PIF difference and, consequently, in a greater (outward) mucus displacement compared with the standard maneuver.

\section{MI-E Ventilation Pattern and Mucus Displacement}

The results of the uni- and multivariate analyses with mucus center-of-mass displacement as the dependent variable are shown in Table 2. During univariate analysis, the PEF: PIF, PEF-PIF difference, type of maneuver (standard vs optimized), and lung-impedance scenarios significantly correlated with mucus displacement (but not the PEF). In multivariate analysis, however, with all variables exhibiting $P<.10$ in the univariate analysis forced into the regression model, only the type of maneuver, PEF-PIF difference, and $+\mathrm{IP} /-\mathrm{EP}$ gradient were significantly correlated with the dependent variable and together explained $81.7 \%$ of mucus displacement $\left(r^{2}=0.817, P<.001\right)$. Analysis of these results indicated that performing a slower insufflation (optimized instead of standard maneuver) and increasing the PEFPIF difference as well as the $+\mathrm{IP} /-\mathrm{EP}$ gradient improve the efficacy of the maneuver, irrespective of the absolute levels of PEF, $+\mathrm{IP}$, or $-\mathrm{EP}$. The results of the multivariate analysis, which show that increments of $+\mathrm{IP} /-\mathrm{EP}$ from $+30 /-30$ $\mathrm{cm}_{2} \mathrm{O}$ to $+40 /-40 \mathrm{~cm} \mathrm{H}_{2} \mathrm{O}$, or to $+50 /-50 \mathrm{~cm} \mathrm{H}_{2} \mathrm{O}$ (ie, just increasing the modulus of inspiratory/expiratory pressures), did not clearly enhance mucus displacement in all scenarios, with both maneuvers, further illustrated in Figure 2. However, increasing $+\mathrm{IP} /-\mathrm{EP}$ gradient (eg, from $+30 /-30 \mathrm{~cm} \mathrm{H}_{2} \mathrm{O}$ to $+30 /-40 \mathrm{~cm} \mathrm{H}_{2} \mathrm{O}$, and to $+30 /-50$ $\mathrm{cm} \mathrm{H}_{2} \mathrm{O}$ ) seemed to improve mucus displacement.

The strong and significant correlation between the PEFPIF difference and mucus center-of-mass displacement are illustrated in Figure 3. It also shows the lack of a correlation between PEF and mucus center-of-mass displacement. In the univariate analysis, + IP was the only variable associated with mucus movement toward the test lungs, although it did not reach statistical significance (Table 2). This result might be explained by the possibility that, the higher the + IP, the greater the PIF, which embeds mucus.

\section{Lung-Impedance and Mucus Displacement}

We found that PEF:PIF and the PEF-PIF difference were lower in the obstructive lung scenario $(P<.001)$, which resulted in a shorter mucus displacement $(P=.03)$ (Table $3)$. Note that also shown in Figure 2 is the shorter mucus displacement in the obstructive scenario compared with the restrictive and normal lung-impedance scenarios.

\section{Optimizing MI-E Therapy During Clinical Practice}

Because MI-E devices do not display peak airway flow values, we removed the PEF-PIF difference from the multivariate regression model to investigate how the remaining 

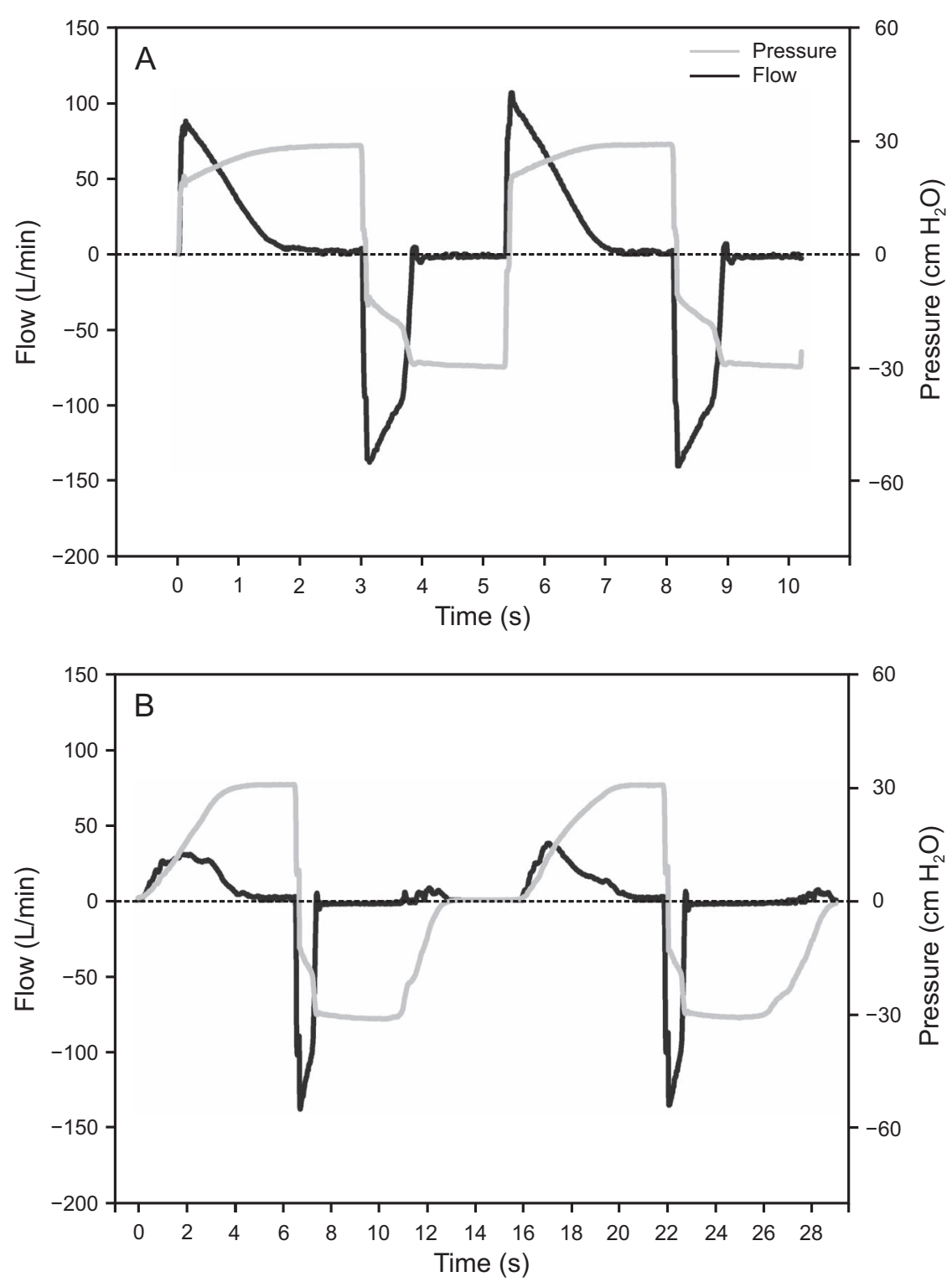

Fig. 1. Pressure and flow curves of two MI-E cycles performed according to the standard (A) and the optimized maneuvers (B).

variables, available in clinical practice, could guide the operator to perform a more-effective maneuver (Table 4). The standardized coefficients revealed that the type of maneuver emerged as the most important variable because performing a slower insufflation had an effect size of $\sim 4$ times higher than the effect of the $+\mathrm{IP} /-\mathrm{EP}$ gradient (coefficients of 0.81 and 0.22 , respectively; $\left.\mathrm{r}^{2}=.705, P<.001\right)$.

\section{Discussion}

In this study, the optimized MI-E maneuver, characterized by a slow insufflation, was more effective in moving mucus outward in a lung model than the standard MI-E maneuver (typically applied with fast insufflation). Moreover, our main results indicated that mucus displacement was strongly correlated with expiratory flow bias and not with PEF alone. Also, we showed that, besides performing the optimized maneuver, mucus clearance with MI-E therapy could also be improved by setting larger MI-E pressure differentials.

Most of the literature regarding MI-E investigated its use in neuromuscular patients with impaired airway clearance, breathing spontaneously, with or without mechanical ventilation assistance. Some studies demonstrated that MI-E is capable of achieving PEF of $>160 \mathrm{~L} / \mathrm{min}$, a threshold for cough efficacy.7,20,21 Two of these studies even indicated that MI-E is more effective than physiotherapyassisted cough ${ }^{7,21}$ at producing this target PEF. ${ }^{7}$ Without questioning this background literature, we demonstrated 
Table 1. Ventilation Variables and Mucus Displacement Achieved During the Standard and Optimized MI-E Maneuvers

\begin{tabular}{lccc}
\hline \hline \multicolumn{1}{c}{ Variable } & $\begin{array}{c}\text { Standard } \\
\text { MI-E Maneuver }\end{array}$ & $\begin{array}{c}\text { Optimized } \\
\text { MI-E Maneuver }\end{array}$ & $P$ \\
\hline$+\mathrm{IP}, \mathrm{cm} \mathrm{H} \mathrm{H}_{2} \mathrm{O}$ & $38.5(30.0-41.8)$ & $38.8(30.6-41.1)$ & .79 \\
$-\mathrm{EP}, \mathrm{cm} \mathrm{H} \mathrm{H}_{2} \mathrm{O}$ & $51.1(59.8-40.7)$ & $50.3(60.7-41.0)$ & .93 \\
$\mathrm{PEF}, \mathrm{L} / \mathrm{min}$ & $153.6(167.5-124.8)$ & $136.8(157.1-108.0)$ & .042 \\
$\mathrm{PIF}, \mathrm{L} / \mathrm{min}$ & $101.8(89.1-115.7)$ & $37.5(24.9-47.9)$ & $<.001$ \\
$\mathrm{~V}_{\mathrm{T}}, \mathrm{mL}$ & $1494(900-1630)$ & $1480(672-1597)$ & .28 \\
$\mathrm{~T}_{\mathrm{I}}, \mathrm{s}$ & $2.94(2.87-3.06)$ & $5.22(4.09-5.70)$ & $<.001$ \\
$\mathrm{PEF}: \mathrm{PIF}$ & $1.44(1.30-1.56)$ & $4.03(2.32-5.90)$ & $<.001$ \\
$\mathrm{PEF}-\mathrm{PIF}$ difference, & $44.9(30.8-58.4)$ & $111.5(59.1-117.0)$ & $<.001$ \\
$\quad$ & & & \\
Lumin & & $3.75(2.68-4.17)$ & $<.001$
\end{tabular}

Values are expressed as median (25-75\% interquartile range).

MI-E = mechanical insufflation-exsufflation

$+\mathrm{IP}=$ insufflation pressure

$-\mathrm{EP}=$ exsufflation pressure

$\mathrm{PEF}=$ peak expiratory flow

$\mathrm{PIF}=$ peak inspiratory flow

$\mathrm{V}_{\mathrm{T}}=$ tidal volume

$\mathrm{T}_{\mathrm{I}}=$ inspiratory time

$\mathrm{CMD}=$ center-of-mass displacement

that, in a lung model that simulated a patient in controlled mechanical ventilation (ie, without spontaneous breathing), to clear pulmonary secretion with MI-E, controlling PEF alone is not enough; we need to control the expiratory flow bias. The median PEF of the optimized MI-E maneuver was lower than the target PEF (137 vs $160 \mathrm{~L} / \mathrm{min}$ ) and even though it effectively cleared mucus. During a voluntary cough, the importance of the expiratory flow bias in secretion clearance may be overshadowed by the fact that PIF is usually much lower than PEF; thus, the PIF influence is minimized and PEF emerges as the key determinant to eliminate secretions present at central airways. However, this is not the case with the standard MI-E maneuver, which, as shown, may result in high PIFs.

We previously showed, in an in vitro experiment, that the PEF-PIF difference seemed to be the best explanatory variable for mucus displacement and that, above a certain threshold (17 L/min), the higher the PEF-PIF difference, the more outward mucus is displaced. ${ }^{12}$ In agreement with our results, Li Bassi et al ${ }^{22}$ demonstrated that mucus clearance, assessed through fluoroscopy tracking of radiopaque markers, improved in pigs on volume-control mechanical ventilation when the PEF-PIF difference was increased from $23.5 \pm 8.6 \mathrm{~L} / \mathrm{min}$ to $33.0 \pm 7.6 \mathrm{~L} / \mathrm{min}$ (mean $\pm \mathrm{SD})$. Therefore, when taking into account airway secretion clearance, it seemed that we had enough data that demonstrated that the inspiratory flow counterpart could not be neglected, especially in patients on mechanical ventilation who are heavily sedated or paralyzed.

There are a few studies that reported the use of MI-E in adult subjects on invasive mechanical ventilation. ${ }^{23-25}$ Gon- çalves et $\mathrm{al}^{24}$ elegantly showed that MI-E minimizes the risk of postextubation secretion encumbrance when applied immediately before extubation. However, to our knowledge, there is no published study that describes MI-E use in patients under controlled mechanical ventilation. One of the reasons that might prevent applying MI-E during controlled mechanical ventilation is that it delivers an $\mathrm{F}_{\mathrm{IO}_{2}}$ of only $21 \%$. If a mechanical ventilator could also work as an MI-E, an idea that is not unrealistic, then this limitation would be extinguished. Moreover, it would also offer other advantages, such as a better respiratory monitoring and spare operators' time because they would not have to set the equipment.

In agreement with our results, Striegl et al, ${ }^{26}$ when using an infant lung model, found that larger MI-E pressure differentials, such as $+20 /-30 \mathrm{~cm} \mathrm{H}_{2} \mathrm{O}$ and $+20 /-40 \mathrm{~cm}$ $\mathrm{H}_{2} \mathrm{O}$, resulted in a higher $\mathrm{PEF}$, which indicated that secretion clearance might be most effectively improved by using asymmetric MI-E pressure settings. The hypothesis that we need higher -EP than + IP to assist with secretion removal is indeed convenient for the purposes of lung protection. It is well known that high inspiratory pressures should be avoided because they can cause hemodynamic instability and alveolar damage. ${ }^{27}$

With regard to our finding that MI-E was less effective when an obstructive lung scenario was simulated, this result was expected. Patients with COPD exhibit expiratory flow limitation due to dynamic airway compression, which compromises PEF augmentation independent of the adjusted pressures. Winck et $\mathrm{al}^{20}$ demonstrated that, in subjects with COPD, MI-E improved oxygenation and breathlessness without a significant improvement in cough peak flow and also without any deterioration in breathing pattern or pulmonary parameters. Therefore, MI-E may be less effective in patients with obstruction when compared with other pulmonary diseases, but it does not mean that use of MI-E provides no benefits to these patients.

In an attempt to translate our results to clinical practice, we could summarized them as follows: (1) insufflation needs to be slowly performed, and (2) the operator should adjust a minimum + IP necessary to guarantee lung expansion and to provide collateral ventilation distal to mucus plugs ${ }^{28}$; beyond this minimum threshold, however, the larger the - EP (within safe limits), the more effective will be the secretion clearance.

\section{Limitations}

This was an in vitro study that required caution to extrapolate our results to the in vivo condition. Our simulated mucus, although previously used by others, ${ }^{12,16}$ was not equivalent to real mucus, which differed and varied markedly in consistency and composition among patients. Moreover, our lung model system tested a single tube 

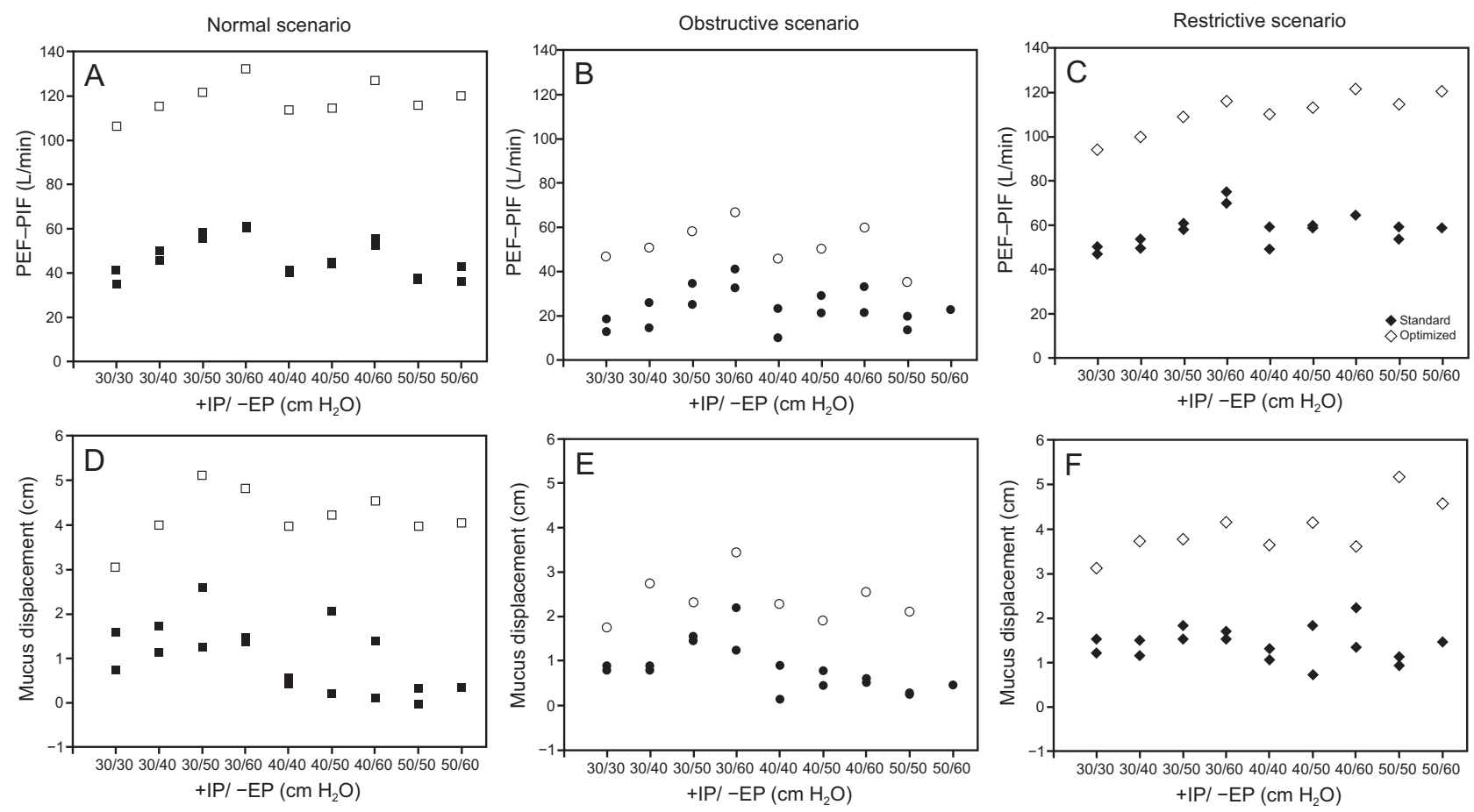

Fig. 2. PEF-PIF difference $(A-C)$ and mucus displacement (D-F) according to mechanical in-exsufflation pressure settings and type of maneuver (optimized vs. standard) in the 3 lung impedance scenarios: normal, obstructive, and restrictive. In D-F, a negative displacement indicates mucus movement toward the test lung. $\mathrm{PEF}=$ peak expiratory flow; PIF $=$ peak inspiratory flow; $+\mathrm{IP} /-\mathrm{EP}=\mathrm{insufflation}$ pressure/exsufflation pressure.

Table 2. Univariate and Multivariate Analyses of Variables Associated With Mucus Simulant Displacement as the Dependent Variable

\begin{tabular}{lccccc}
\hline \hline \multirow{2}{*}{ Variable } & \multicolumn{2}{c}{$\begin{array}{c}\text { Univariate } \\
\text { Analysis }\end{array}$} & & \multicolumn{2}{c}{$\begin{array}{c}\text { Multivariate } \\
\text { Analysis }\end{array}$} \\
\cline { 2 - 3 } \cline { 5 - 6 } & $\beta^{*}$ & $P$ & & $\beta^{*}$ & $P$ \\
\hline Type of maneuver $\dagger$ & 0.811 & $<.001$ & & 0.511 & $<.001$ \\
PEF-PIF difference & 0.859 & $<.001$ & & 0.485 & .001 \\
PEF:PIF & 0.768 & $<.001$ & & -0.076 & .48 \\
Lung impedance $\neq$ & 0.296 & .008 & & 0.063 & .50 \\
+ IP/-EP gradient & 0.203 & .08 & & 0.128 & .031 \\
PEF & 0.054 & .64 & & \\
+ IP & -0.170 & .14 & & \\
-EP & 0.082 & .48 & &
\end{tabular}

* Standardized coefficients.

$\uparrow$ The codes used in the regression analysis for the optimized and standard maneuver were 1 and 0 , respectively; thus, a positive $\beta$ indicates that the use of optimized maneuver enhanced the removal of secretions.

$\$$ The codes used in the regression analysis for the obstructive and restrictive lung scenarios were -1 and 1 , respectively; thus, the removal of secretions was higher during a restrictive scenario.

$\mathrm{PEF}=$ peak expiratory flow

$\mathrm{PIF}=$ peak inspiratory flow

$+\mathrm{IP}=$ insufflation pressure

$-\mathrm{EP}=$ exsufflation pressure

diameter that imitated the dimensions of a human trachea (10 $\mathrm{mm})$ positioned horizontally. Thus, the composed effects of tracheal tubes inside the trachea, with smaller inner diameters, and submitted to some gravity influence, because the human trachea has an oblique course, were not precisely investigated. Tracheal tubes with 7.5-8.5 mm inner diameters, which are usually used in clinical practice, increase airway resistance and may require a longer $\mathrm{T}_{\mathrm{I}}$ to deliver optimum lung expansion with MI-E. ${ }^{29}$

Because the optimized MI-E maneuver required a longer $\mathrm{T}_{\mathrm{I}}$ to deliver low PIFs, its performance in patients with smaller tracheal tubes might excessively prolong $\mathrm{T}_{\mathrm{I}}$, which causes patient discomfort and precludes its application. However, we believed that $\mathrm{T}_{\mathrm{I}}$ could be adjusted according to patient's comfort and still result in lower PIFs to improve MI-E therapy. With regard to the effects of gravity, patients who are critically ill are usually placed in the semirecumbent position, which places the extrathoracic trachea almost parallel to the bed (elevated to $45^{\circ}$ ), while the intrathoracic trachea is $\sim 20^{\circ}$ more vertical. ${ }^{30}$ Such positioning has already been shown to impair oropharyngeal secretion removal ${ }^{30,31,32}$ and would probably require a higher expiratory flow bias to displace mucus outward against gravity with the optimized MI-E maneuver. Thus, the adjunctive use of different positioning (to minimize gravity) during the optimized MI-E maneuver warrants further investigation.

Also, the slower insufflation in the optimized MI-E maneuver was not controlled and was obtained by slowly 

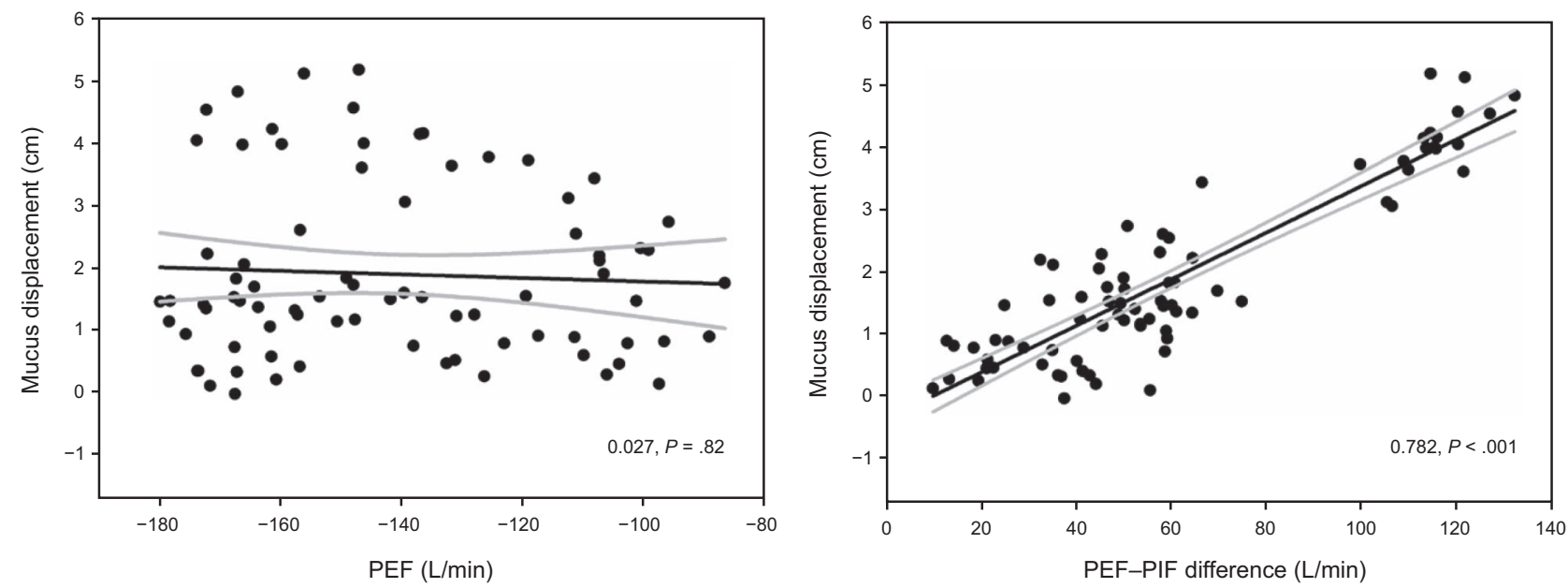

Fig. 3. Relationship of center-of-mass displacement to PEF-PIF difference and PEF. A negative displacement indicates mucus movement towards the test lung. Curve-fitting analysis is shown in black, with $95 \% \mathrm{Cl}$ in gray. PEF = peak expiratory flow; PIF = peak inspiratory flow.

Table 3. MI-E Ventilation Variables and Mucus Displacement Achieved During the 3 Lung-Impedance Scenarios

\begin{tabular}{|c|c|c|c|c|}
\hline Variable & Normal Scenario & Obstructive Scenario & Restrictive Scenario & $P$ \\
\hline$+\mathrm{IP}, \mathrm{cm} \mathrm{H}_{2} \mathrm{O}$ & $38.6(29.9-41.9)$ & $37.3(30.0-40.7)$ & $38.9(30.7-41.9)$ & .55 \\
\hline$-\mathrm{EP}, \mathrm{cm} \mathrm{H}_{2} \mathrm{O}$ & $51.1(60.8-40.9)$ & $50.4(56.0-39.7)$ & $51.3(60.7-40.7)$ & .57 \\
\hline $\mathrm{PEF}, \mathrm{L} / \mathrm{min}$ & $161.6(167.6-156.2)$ & 107.4 (118.5-99.9) & $149.2(167.8-136.7)$ & $<.001$ \\
\hline $\mathrm{PIF}, \mathrm{L} / \mathrm{min}$ & $102.6(47.0-120.3)$ & $82.9(55.2-90.6)$ & $92.9(25.2-107.9)$ & .050 \\
\hline $\mathrm{V}_{\mathrm{T}}, \mathrm{mL}$ & $1612(1494-1675)$ & $1567(1488-1639)$ & $697(532-836)$ & $<.001$ \\
\hline $\mathrm{T}_{\mathrm{I}}, \mathrm{s}$ & $3.01(2.90-5.47)$ & $2.94(2.86-3.48)$ & $3.09(2.96-5.02)$ & .08 \\
\hline PEF:PIF & $1.52(1.37-3.47)$ & $1.34(1.22-1.87)$ & $1.62(1.54-5.89)$ & $<.001$ \\
\hline PEF-PIF difference, $\mathrm{L} / \mathrm{min}$ & $55.5(41.5-114.5)$ & $29.1(20.4-46.0)$ & $60.8(57.9-108.9)$ & $<.001$ \\
\hline Mucus CMD, $\mathrm{cm}^{*}$ & $1.46(0.41-3.98)$ & $0.90(0.55-2.15)$ & $1.53(1.31-3.63)$ & .055 \\
\hline
\end{tabular}

Values are expressed as median (25-75\% interquartile range).

* When considering a parametric test for the transformed variable (square root of CMD) that complies with normality assumptions, we observed a $P=.028$.

MI-E = mechanical insufflation-exsufflation

$+\mathrm{IP}=$ insufflation pressure

$-\mathrm{EP}=$ exsufflation pressure

$\mathrm{PEF}=$ peak expiratory flow

$\mathrm{PIF}=$ peak inspiratory flow

$\mathrm{V}_{\mathrm{T}}=$ tidal volume

$\mathrm{T}_{\mathrm{I}}=$ inspiratory time

$\mathrm{CMD}=$ center-of-mass displacement

Table 4. Multivariate Analysis After PEF-PIF Difference Removal With Mucus Simulant Displacement as the Dependent Variable

\begin{tabular}{ccr}
\hline \hline \multirow{2}{*}{ Variable } & \multicolumn{3}{c}{$\begin{array}{c}\text { Multivariate } \\
\text { Analysis }\end{array}$} \\
\cline { 2 - 3 } & $\beta^{*}$ & \multicolumn{1}{c}{$P$} \\
\hline Type of maneuver $\dagger$ & 0.815 & $<.001$ \\
+IP/-EP gradient & 0.218 & .001
\end{tabular}

* Standardized coefficients.

$\dagger$ The codes used in the regression analysis for the optimized and standard maneuver were 1 and 0 , respectively; thus, a positive $\beta$ indicates that the use of an optimized maneuver enhanced the removal of secretions.

$\mathrm{PEF}=$ peak expiratory flow

$\mathrm{PIF}=$ peak inspiratory flow

$+\mathrm{IP}=$ insufflation pressure

$-\mathrm{EP}=$ exsufflation pressure shifting the control lever to the inhale position. This might difficult the reproducibility of the maneuver. However, this limitation could be easily overcome with some practice, as indicated by our results. It is important to emphasize that our study was designed as an initial step to establish conceptual principles to optimize airway clearance with MI-E and to direct further studies on efficacy, safety, and feasibility of this maneuver in vivo experiments.

\section{Conclusions}

The optimized MI-E maneuver, applied with slow insufflation, was more effective in moving secretions outward in a lung model than the standard MI-E maneuver, 
typically applied with fast insufflation. This accomplishment was the result of a higher expiratory flow bias, which seemed to be the key determinant of mucus clearance, irrespective of PEF.

\section{REFERENCES}

1. Homnick DN. Mechanical insufflation-exsufflation for airway mucus clearance. Respir Care 2007;52(10):1296-1305; discussion 13061307.

2. Auger C, Hernando V, Galmiche H. Use of Mechanical InsufflationExsufflation Devices for Airway Clearance in subjects With Neuromuscular disease. Respir Care 2017;62(2):236-245.

3. Andersen T, Sandnes A, Hilland M, Halvorsen T, Fondenes O, Heimdal $\mathrm{JH}$, et al. Laryngeal response patterns to mechanical insufflationexsufflation in healthy subjects. Am J Phys Med Rehabil 2013; 92(10):920-929.

4. Bach JR, Saporito LR. Criteria for extubation and tracheostomy tube removal for patients with ventilatory failure. A different approach to weaning. Chest 1996;110(6):1566-1571.

5. Bach JR. Mechanical insufflation/exsufflation: has it come of age? A commentary. Eur Respir J 2003;21(3):385-386.

6. Gómez-Merino E, Sancho J, Marín J, Servera E, Blasco ML, Belda FJ, et al. Mechanical insufflation-exsufflation: pressure, volume, and flow relationships and the adequacy of the manufacturer's guidelines. Am J Phys Med Rehabil 2002;81(8):579-583.

7. Chatwin M, Ross E, Hart N, Nickol AH, Polkey MI, Simonds AK. Cough augmentation with mechanical insufflation/exsufflation in patients with neuromuscular weakness. Eur Respir J 2003;21(3):502508

8. Kim CS, Iglesias AJ, Sackner MA. Mucus clearance by two-phase gas-liquid flow mechanism: asymmetric periodic flow model. J Appl Physiol 1987;62(3):959-971.

9. Benjamin RG, Chapman GA, Kim CS, Sackner MA. Removal of bronchial secretions by two-phase gas-liquid transport. Chest 1989; 95(3):658-663.

10. Kim CS, Greene MA, Sankaran S, Sackner MA. Mucus transport in the airways by two-phase gas-liquid flow mechanism: continuous flow model. J Appl Physiol 1986;60(3):908-917.

11. Freitag L, Long WM, Kim CS, Wanner A. Removal of excessive bronchial secretions by asymmetric high-frequency oscillations. J Appl Physiol 1989;67(2):614-619.

12. Volpe MS, Adams AB, Amato MB, Marini JJ. Ventilation patterns influence airway secretion movement. Respir Care 2008;53(10):12871294.

13. Kim CS, Rodriguez CR, Eldridge MA, Sackner MA. Criteria for mucus transport in the airways by two-phase gas-liquid flow mechanism. J Appl Physiol 1986;60(3):901-907.

14. Volpe MS, Amato MB. Is it time to monitor flow bias during mechanical ventilation? Respir Care 2011;56(12):1970-1971.

15. Toussaint $M$. The use of mechanical insufflation-exsufflation via artificial airways. Respir Care 2011;56(8):1217-1219.

16. Shah S, Fung K, Brim S, Rubin BK. An in vitro evaluation of the effectiveness of endotracheal suction catheters. Chest 2005;128(5): 3699-3704.
17. Bach JR. Amyotrophic lateral sclerosis: prolongation of life by noninvasive respiratory AIDS. Chest 2002;122(1):92-98.

18. Bento J, Gonçalves M, Silva N, Pinto T, Marinho A, Winck JC. [Indications and compliance of home mechanical insufflation-exsufflation in patients with neuromuscular diseases]. Arch Bronconeumol 2010;46(8):420-425

19. Crew JD, Svircev JN, Burns SP. Mechanical insufflation-exsufflation device prescription for outpatients with tetraplegia. J Spinal Cord Med 2010;33(2):128-134.

20. Winck JC, Gonçalves MR, Lourenço C, Viana P, Almeida J, Bach JR. Effects of mechanical insufflation-exsufflation on respiratory parameters for patients with chronic airway secretion encumbrance. Chest 2004;126(3):774-780.

21. Bach JR. Mechanical insufflation-exsufflation. Comparison of peak expiratory flows with manually assisted and unassisted coughing techniques. Chest 1993;104(5):1553-1562.

22. Li Bassi G, Saucedo L, Marti JD, Rigol M, Esperatti M, Luque N, et al. Effects of duty cycle and positive end-expiratory pressure on mucus clearance during mechanical ventilation*. Crit Care Med 2012; 40(3):895-902.

23. Bach JR, Goncalves M. Ventilator weaning by lung expansion and decannulation. Am J Phys Med Rehabil 2004;83(7):560-568.

24. Gonçalves MR, Honrado T, Winck JC, Paiva JA. Effects of mechanical insufflation-exsufflation in preventing respiratory failure after extubation: a randomized controlled trial. Crit Care 2012;16(2):R48.

25. Bach JR, Sinquee DM, Saporito LR, Botticello AL. Efficacy of mechanical insufflation-exsufflation in extubating unweanable subjects with restrictive pulmonary disorders. Respir Care 2015;60(4): 477-483.

26. Striegl AM, Redding GJ, Diblasi R, Crotwell D, Salyer J, Carter ER. Use of a lung model to assess mechanical in-exsufflator therapy in infants with tracheostomy. Pediatr Pulmonol 2011;46(3):211-217.

27. Anzueto A, Frutos-Vivar F, Esteban A, Alía I, Brochard L, Stewart $\mathrm{T}$, et al. Incidence, risk factors and outcome of barotrauma in mechanically ventilated patients. Intensive Care Med 2004;30(4):612619.

28. McIlwaine M, Bradley J, Elborn JS, Moran F. Personalising airway clearance in chronic lung disease. Eur Respir Rev 2017;26(143): pii: 160086 .

29. Guérin C, Bourdin G, Leray V, Delannoy B, Bayle F, Germain M, Richard JC. Performance of the coughassist insufflation-exsufflation device in the presence of an endotracheal tube or tracheostomy tube: a bench study. Respir Care 2011;56(8):1108-1114.

30. Zanella A, Cressoni M, Epp M, Hoffmann V, Stylianou M, Kolobow T. Effects of tracheal orientation on development of ventilator-associated pneumonia: an experimental study. Intensive Care Med 2012; 38(4):677-685.

31. Li Bassi G, Zanella A, Cressoni M, Stylianou M, Kolobow T. Following tracheal intubation, mucus flow is reversed in the semirecumbent position: possible role in the pathogenesis of ventilatorassociated pneumonia. Crit Care Med 2008;36(2):518-525.

32. Li Bassi G, Torres A. Ventilator-associated pneumonia: role of positioning. Curr Opin Crit Care 2011;17(1):57-63.

This article is approved for Continuing Respiratory Care Education credit. For information and to obtain your CRCE

(free to AARC members) visit www.rcjournal.com

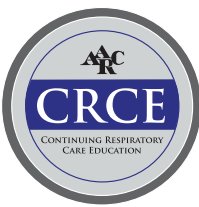

